\title{
Content Analysis of the Civics Textbook in Iran and Providing a Theoretical Framework for the Appropriate Criteria of Determining Content according to the
} Teachers and Authors' View

\author{
Mohammad Hosein Saket ${ }^{1 *}$
}

\section{ABSTRACT}

Background: Textbook, which is considered as one of the most important sources of students' learning in educational systems has also an important role in the educational system of Iran. Purpose: the present study was conducted for the content analysis of the civics textbook in Iran and providing a theoretical framework for the appropriate criteria of determining content according to the teachers and authors (based on gender). Methodology: the present study was conducted in the form of causal-comparative study and compilation of questionnaires and content analysis. The analysis was done based on the items of the questionnaire. For this purpose, two groups consisted of 107 male and female teachers who were teaching in the public, non-profit and Shahid schools in Tehran were selected using cluster sampling method. In addition, the six authors of the books mentioned working in the research and educational planning department of the Ministry of Education were selected based on target sampling. Due to the nature of the survey, the researcher-developed questionnaire including 32 items was completed by the participants. The present study was conducted using the statistical method of descriptive analysis by which the data was collected, classified and organized and underwent content analysis using the checklist. Result: the results of the present study offered a theoretical pattern of three sections based on society, individual and subject. Findings: theoretical integrity can be considered important in formulating and preparing the texts element which improves the education vision in the long run.

Keywords: Primary Education, Civics, Content Analysis, Primary School, Appropriate Criteria, Teachers' Vision.

\footnotetext{
${ }^{1}$ Conventional Master, University of Applied Science, Tehran, Iran

*Responding Author

(C) 2016 I M Saket; licensee IJIP. This is an Open Access Research distributed under the terms of the Creative Commons Attribution License (http://creativecommons.org/licenses/by/2.0), which permits unrestricted use, distribution, and reproduction in any Medium, provided the original work is properly cited.
} 


\section{Content Analysis of the Civics Textbook in Iran and Providing a Theoretical Framework for the Appropriate Criteria of Determining Content according to the Teachers and Authors' View}

Content analysis is one of the mostly used among research methods in social science studies and human behavior. In the current educational system of Iran textbooks are the most important learning tool and curriculum content. Therefore, it is necessary to examine the content of textbooks, for various reasons, such as compliance with objectives to identify strengths and weaknesses of the curriculum or textbooks. This study can be done in different ways among which content analysis was the most common method. On the other hand the term Social Studies means the study of society and human being. The term was first used in the early twentieth century. In 1920 social studies was set as a subject into the curriculum and since 1960, countries of the world gradually revealed the desire to teach this lesson. In this connection, in order to have a good education quality, the educational materials and practices must be changed so that the mental and practical abilities of the educators and learners can be used (Hakim, et al., 2007). Creating this awareness is the most important factor guiding social behavior during adolescence and adulthood (Hastings et al., 2000, Naeli, 1994). The sensitivity of this issue becomes more when we knew that in most cases the textbook is the only learning media in the process of teaching and learning in children (Zamani, 2006). In fact, the content is the main part of the education program and has always been of interest to the experts. Therefore, having good and appropriate content of a learning subject makes the accomplishment of the goals possible. Teachers, officials, planners and experts are always asking about the content of textbooks and for example ask that what content or subject should be taught? How it can be taught? And finally why this content or subject should be taught?

As it is well known, the educational system of Iran has always been book-oriented. Accordingly, the textbook content has always been an important element of the curriculum in this country. According to what was mentioned above, the present study aimed to conduct a content analysis of the civics textbook in Iran and provide a theoretical framework for the appropriate criteria of determining content according to the teachers and authors' view. The results of the research can be used by teachers, programmers and authors as well.

\section{RESEARCH METHOD}

Regarding the research purpose, the present study was conducted based on the method of content analysis. That is, in this regard, the subject of civics in Elementary School using the checklist was undergone the content analysis. After examining the views of teachers and comparing them with the views of the book authors, the common points of this assessment were excluded and then, the analysis was presented in the form of a theoretical framework.

\section{Research Population and Sampling Method}

Population of the study included all the male and female teachers of the primary school in the 19 districts of Tehran, Iran in the Social Studies of the third grade and all the authors of the book working in the Research and Educational Planning Organization of the Ministry of Education. Considering the research nature, research participants were selected using cluster sampling method. For this purpose, three schools have been selected from each district and then the 


\section{Content Analysis of the Civics Textbook in Iran and Providing a Theoretical Framework for the Appropriate Criteria of Determining Content according to the Teachers and Authors' View}

questionnaires were distributed among male and female teachers. After collecting the questionnaires and examining the required criterion, 107 questionnaires were included in the research. Further, 6 authors were selected based on targeted selection from among the authors working in the Research and Educational Planning Organization of the Ministry of Education based on the abilities considered by the researcher.

\section{Method of Data Collection}

The present study was conducted by performing the administrative procedures and direct visits with the research scholar of the selected schools. After coordination with school principals, questionnaires were distributed between male and female teachers and then were analyzed. In order to collect the data related to authors of social studies textbooks of the third grade. For required coordination, the researcher contacted the curriculum office of the Department of Social Studies Ministry of Education.

In order to extract the criteria for content selection, the opinions of the male and female teachers were examined via questionnaires and then were compared with the opinions of the authors. For this purpose, perfectly acceptable criteria were the answers with higher than the 65\% approval. The acceptable criteria for answers were those approved over 50\% to 65\%, respectively, and finally criteria for weak responses were those with lower than 50\% approval, respectively. Then the common responses were analyzed and theoretical model was offered about the content of the courses.

\section{Research Instrument}

The instrument for data collection used in this study consists of a questionnaire designed as below:

\section{Questionnaire of the male and female teachers}

Questionnaire of the male and female teachers included 32 items based on a five-point Likert scale with five choices in response including very high, high, low, very low and ineffective. The items of the questionnaire fall into two general categories which are mostly related to content and small part of the questions is related to the learning experiences. The content questions include lesson content and some final questions at the end of the lesson.

\section{Questionnaire of the authors}

Questionnaire of the authors included 32 items based on a five-point Likert scale with five choices in response including very high, high, low, very low and ineffective. The items of the questionnaire fall into the content rather than the learning experiences.

Both the validity and reliability of the questionnaire were evaluated and its reliability using Cronbach's alpha coefficient was estimated as 0.78 and hence was not acceptable (Khosravi, 


\section{Content Analysis of the Civics Textbook in Iran and Providing a Theoretical Framework for the Appropriate Criteria of Determining Content according to the Teachers and Authors' View}

1997).

\section{Method of Data Analysis}

In order to analyze the data, descriptive and inferential statistics were applied. The research computing in the descriptive statistics included the determination of the frequency and percentage of female and male teachers' responses to the questionnaire and the analysis of the responses of teachers and authors of the textbooks on each questions of the questionnaire.

The Chi-square test was used for analysis of the inferential data in order to determine the relationship between male and female teachers as well as teachers with the authors of the book social studies for third grade in responding to the questions and determining the statistical significance of differences (Shivellson 1987).

Since the expected theoretical frequency of some choices was less than 5, they were merged so the high and very high options were set in one group and very low, low and ineffective in another group. Data contingency table $2 \times 2$ was set with one degree of freedom. If the frequency of each group was less than 10 the modified Yates formula was used (Sharifi and Zand, 1991).

\section{RESULTS}

After collecting the opinions of teachers and authors, because of the high number of classes, the integration of adjacent houses and homes in the form of three criteria perfectly acceptable, acceptable and poor were developed. The components were analyzed by descriptive method and were summarized in the educational model.

\section{Common criteria considered by male and female teachers}

A) fully accepted criteria included: to have understandable content, logical sequence in the context of a clear direction, to familiarize the students with the rules and regulations of society, effects of teachers' teaching method in better learning, considering content according to the rule of Islamic culture and values, being targeted content and generate interest in students.

B) The criteria for acceptability: considering the content based on cultural diversity and geographical environment, strengthen the social adjustment of students, considering the social needs of students, the importance of basic ideas, and considering the public needs.

C) The criteria for weakness : the correct balance of the content, reinforcing the curiosity in students, the relatedness of the content with everyday problems of society, the scientific spirit, considering the the student's past experiences, lessons should be associated with higher grades, considering the student's physical and mental needs, innovation and creativity and paying attention to the minority groups. 
Content Analysis of the Civics Textbook in Iran and Providing a Theoretical Framework for the Appropriate Criteria of Determining Content according to the Teachers and Authors' View

\section{Common criteria considered by teachers and authors}

A) Completely accepted criteria: according to the rule of Islamic culture and values, to understand the content, direction and logical sequence in the content, create interest in learning, considering the content of cultural diversity, environmental and geological, to familiarize students with the rules and society law, developed on the basis of objective educational content.

B) Acceptable criteria: the Effect of teachers' teaching method on students' better learn, considering the characteristics and the age of the students, the importance of the fundamental ideas rather than the mass transfer of scientific facts, to foster a sense of curiosity and research and finally considering the mental abilities of students.

C) The criteria of weaknesses: considering the social needs, the growth of cooperation spirit, acceptance of the status quo by students, content associated with basic higher education, according to the general needs of the people, paying attention to the student's past experiences, according to the psychological needs, relatedness with the lower core modules.

The final comments of teachers and authors to select appropriate content is expressed in the following where two cases are related to the students and three cases are related to the society and five cases related to the subject matter.

Table 1. Common theoretical model, teachers and authors common opinion about the content of the lesson in civics

\begin{tabular}{|c|c|c|}
\hline \multirow{10}{*}{$\begin{array}{l}\text { Criteria for the selection and } \\
\text { content }\end{array}$} & \multirow[b]{2}{*}{ person } & Mental abilities \\
\hline & & Age characteristics \\
\hline & \multirow{3}{*}{ Society } & $\begin{array}{l}\text { Rules and regulations of the } \\
\text { Society }\end{array}$ \\
\hline & & $\begin{array}{l}\text { Geographical, cultural and } \\
\text { environmental diversity }\end{array}$ \\
\hline & & Social adjustment \\
\hline & \multirow{5}{*}{ Learning subject } & Comprehensibility \\
\hline & & $\begin{array}{l}\text { Clear direction and logical } \\
\text { ability }\end{array}$ \\
\hline & & Impact on learning method \\
\hline & & Educational objectives \\
\hline & & Creating interest \\
\hline
\end{tabular}

Providing a theoretical model (based on the three sources) 


\section{Content Analysis of the Civics Textbook in Iran and Providing a Theoretical Framework for the Appropriate Criteria of Determining Content according to the Teachers and Authors' View}

In the following, the criteria derived from three sources, according to the ideas of female teachers, male teachers and authors of the civics textbook for the third-grade primary school were accepted in terms of fully accepted and agreed to provide the ultimate theoretical model.

Table 2 - Selected theoretical model presented in the context of selecting appropriate content in social studies

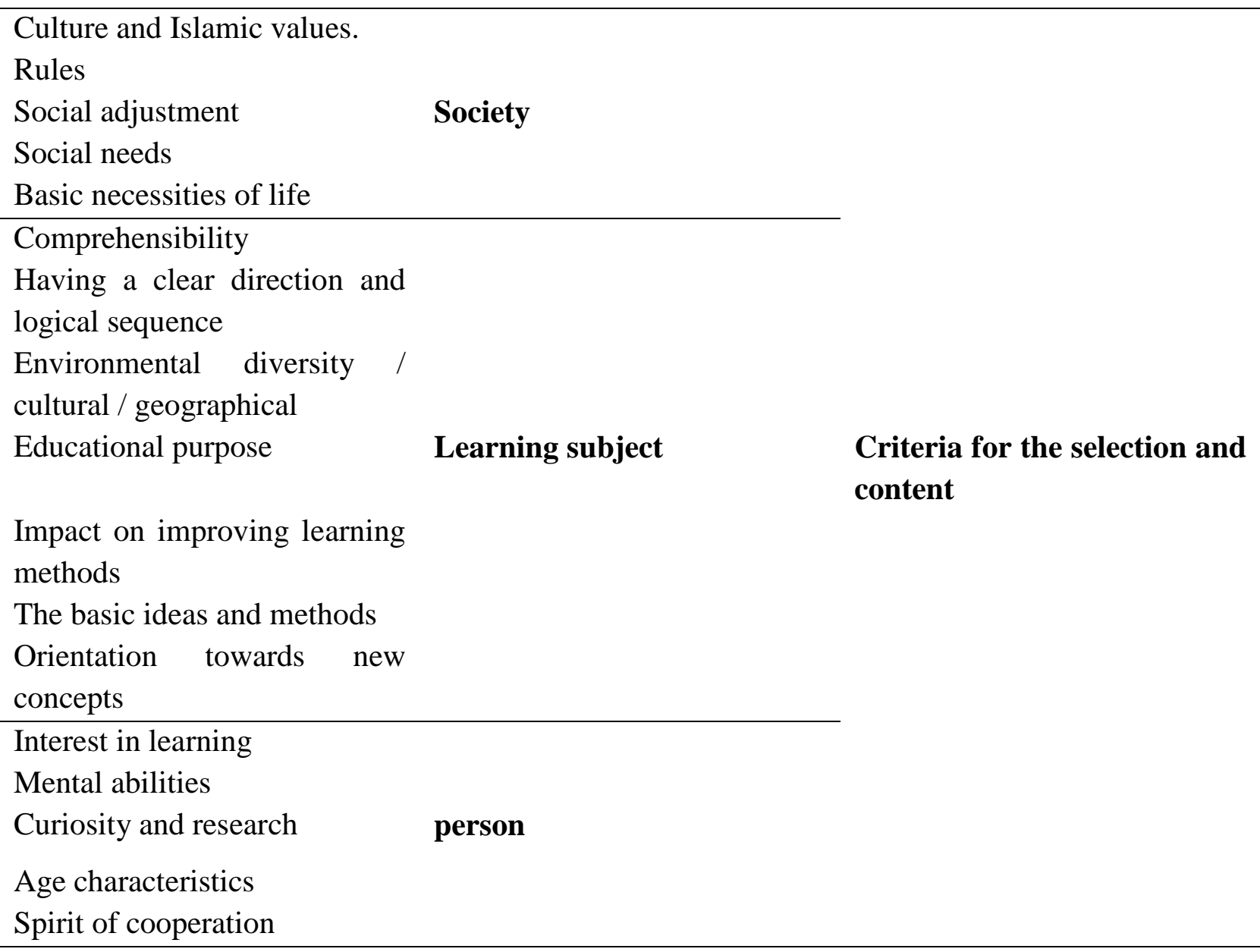

\section{RESULTS AND DISCUSSION}

The present study aimed to provide a theoretical framework about the choice of appropriate content for the learning subject of social studies, third-grade primary school in Iran. The results were presented in the form of a theoretical model in three sectors of society, person and learning subject. Regarding the category of society five factors were provided including culture and Islamic values, rules and regulations, social adjustment, social needs and general living necessities. Regarding learning subject understood seven components were processed including having a clear direction and logical sequence, environmental diversity / cultural / geographic, educational purpose, impact on improving learning methods, basic ideas and orientation towards new concepts. 


\section{Content Analysis of the Civics Textbook in Iran and Providing a Theoretical Framework for the Appropriate Criteria of Determining Content according to the Teachers and Authors' View}

Finally, in section of five individual index, the components of interest in learning, mental abilities, curiosity and research, age and growth characteristics and spirit of cooperation were developed and extracted. Although no similar study is found in the literature, in this section a summary of the studies related to the study are presented. Maleki (1989) in a study entitled “ Comparison of primary school civics program in Iran, Australia and America" came to the conclusion that the principles of setting schedules for achieving better learning experiences in social science books of U.S.A. was better than Australia and in Australia was better than Iran. In other words, in Iran no practical activity has been predicted for students and the curriculum in Iran have been evaluated as very low quality in terms of being practical. Maleki, In another study entitled as "providing a theoretical framework for organizing the content of the curriculum with an emphasis on civics curriculum" has stated that by setting the goals, organization and successive planning of learning experiences one can provided the required conditions favorable for the content social studies at schools .

Sharaf Bayani (1995) in a study entitled as the "Analysis of the content of social studies books of the first and second grade of secondary school from the perspective of the teachers and the authors" concluded that there were serious problems in the collection of these books in teaching and decision-making process.

Hakimzadeh et al (2007) conducted as study entitled as "textbook content analysis according to the International Day of topics in the curriculum" concluded that although attention has been paid to environmental education more than what is expected, however, there are several components which have not been considered in a balanced way.

Hosseini-Nasab and Dehgan (2008) in a study entitled as "content analysis of the middle school civics textbook based on social skills and perspectives of teachers", after considering environmental education as one of the social skills, came to the conclusion that the social skills in civics books were evaluated as moderate and low. The findings of this study can be used in defining the educational perspective based on the needs and potentials and improvement in the educational process mark.

\section{LIMITATIONS OF THE STUDY}

Since the limitations of the research are highly important. The limitations have been divided into two parts, one for the researcher and the other one was out of control of the researcher. A - the limitations of the research: (1) limiting the study to the third-grade social studies teacher (2) limiting the statistical population to nineteen regions in Tehran and (3) limiting the statistical population to practitioners and authors of textbooks of the third grade social studies book contents.

B) Limitations out of the researcher control included 


\section{Content Analysis of the Civics Textbook in Iran and Providing a Theoretical Framework for the Appropriate Criteria of Determining Content according to the Teachers and Authors' View}

1. The limitation of sampling; 2. No timely access to teachers due to their presence in the classroom; 3. Dispersion and differentiation of schools and districts which makes it difficult to have access to more schools at different times: 4 . the communication problems with schools of female students due to Islamic and school principals.

\section{RECOMMENDATIONS FOR FUTURE RESEARCH}

The course Social Studies is a complement to other courses, so that it should be considered by other courses so that the interactive effects can be evaluated. It is required that the future studies use a wider range of teachers and authors of textbooks and teaching experience should be considered as an index in the selection of teachers as an important component.

\section{Acknowledgments}

The author appreciates all those who participated in the study and helped to facilitate the research process.

\section{Conflict of Interests}

The author declared no conflict of interests.

\section{REFERENCES}

Arizi Samani, H., and Abedi, A., Content analysis of primary school textbooks in terms of structure, motivation and development

Hakimzade, R ., Kiamanesh A., and Attaran M., Content Analysis of school textbooks based one the global problems and issues in the field of curriculum

Hosseininasab, D., and Dehghani, M., Content analysis of middle school social studies books on social skills and attitudes of teachers about the content of the above-mentioned books.

Khosravi, A., 1997, PhD thesis, A theoretical framework for the basic standards of choice of content and learning experiences in the social studies curriculum in first, second and third grade of secondary school in Iran, Islamic Azad University.

Maleki, H., 1995, organizing the content of the curriculum with an emphasis on social studies, Tehran, Swan publication.

Maleki, H., 1997, Curriculum (Practical Guide), printing, Tehran, school publications

Sariatmadari, A., 1998. Society and education, Third Edition, Tehran, Amir Kabir Publications

Tabari, Sh., 1974, comparative assessment of students social knowledge in urban, rural and nomadic groups

How to cite this article: M Saket (2016), Content Analysis of the Civics Textbook in Iran and Providing a Theoretical Framework for the Appropriate Criteria of Determining Content according to the Teachers and Authors' View, International Journal of Indian Psychology, Volume 3, Issue 3, No. 5, DIP: 18.01.092/20160303 